\title{
Human fascioliasis due to Fasciola hepatica in Kurdistan, Iran: A case report
}

\author{
Shahla Afrasiabian', Bayazid Ghaderi ${ }^{2}$, Asrin Babahajian ${ }^{3}$, Gohar Lotfi $^{4}$, Fares Bahrami $^{5}$
}

1. Associate Professor, Zoonoses Research Center, Research Institute for Health Development, Kurdistan University of Medical Sciences, Sanandaj, Iran., (Corresponding Author), Tel: +98-87-33664958, shahlaafra@yahoo.com, ORCID ID: 0000-0002-5352-4604

2. Associate Professor, Liver and Digestive Research Center, Research Institute for Health Development, Kurdistan University of Medical Sciences, Sanandaj, Iran. ORCID ID: 0000-0001-9174-829X

3. MSc of Anatomical Sciences, liver and Digestive Research Center, Research Institute for Health Development, Kurdistan University of Medical Sciences, Sanandaj, Iran. ORCID ID: 0000-0003-0278-1560

4. Assistant Professor, Department of Infectious Diseases, Faculty of Medicine, Kurdistan University of Medical Sciences, Sanandaj, Iran. ORCID ID: 0000-0001-7246-2886

5. Assistant Professor, Zoonoses Research Center, Research Institute for Health Development, Kurdistan University of Medical Sciences, Sanandaj, Iran. ORCID ID: 0000-0002-4490-1412

\begin{abstract}
Background and Aim: Human fascioliasis is a water and food-borne parasitic disease and has become endemic in the coastal provinces of Caspian Sea. Limited reports of the disease and its diagnosis have resulted in ignoring the disease and a significant rise in the number of neglected patients in other parts of the country.

Case presentation: In this study, a 50-year-old man living in a village of Kamyaran, in Kurdistan Province in Iran referred to hospital with complaints of weight loss, epigastric pain and anorexia from two months ago. The patient reported history of consuming raw vegetables and plant foods. Laboratory studies revealed anemia, leukocytosis, eosinophilia, high ESR, low serum iron and elevated liver enzymes. Spiral CT scan of liver, showed hypodense areas without enhancement in the arterial phase and with relative homogeneous enhancement in the delayed phase. Ultrasound studies showed multiple hetero and hyper-echoic areas without walls in different parts of the liver. Finally, Fasciola hepatica was diagnosed after stool examination by formalin ether concentration method and also positive ELISA test. The patient was treated with triclabendazole $500 \mathrm{mg} /$ day for two days. In the follow-up the clinical status of the patient was better and we found improved laboratory test results.

Conclusion: The present report highlights the need for paying more attention to the occurrence of this disease in Kurdistan Province by health care systems.
\end{abstract}

Keywords: Human fascioliasis, Fasciola hepatica, Kurdistan, Iran

Received: Apr 3, 2021

Accepted: June 14, 2021

How to cite the article: Shahla Afrasiabian, Bayazid Ghaderi, Asrin Babahajian, Gohar Lotfi, Fares Bahrami. Human fascioliasis due to Fasciola hepatica in Kurdistan, Iran: A case report. SJKU . 2021;26(3):170-176.

Copyright @ 2018 the Author (s). Published by Kurdistan University of Medical Sciences. This is an open access article distributed under the terms of the Creative Commons Attribution-Non-Commercial License 4.0 (CCBYNC), where it is permissible to download, share, remix, transform, and buildup the work provided it is properly cited. The work cannot be used commercially without permission from the journal 


\section{كزارش يك مورد فاسيوليازيس كبدى ناشى ازفاسيولا هياتيكا در استان كردستان،}

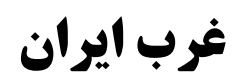

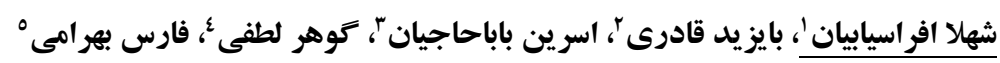

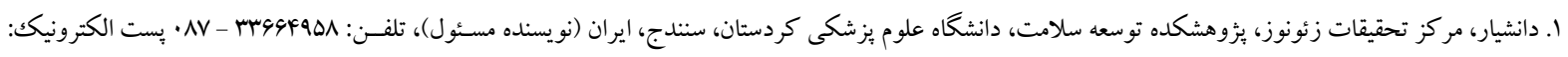
........r-arar-rq.r.F shahlaafra@yahoo.com

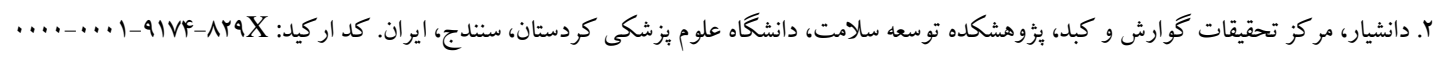

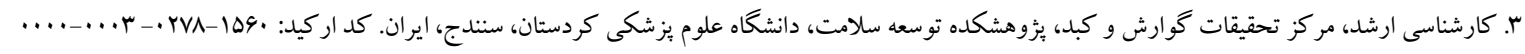

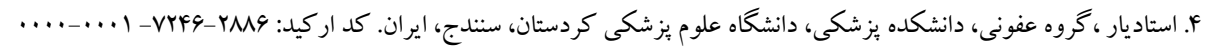

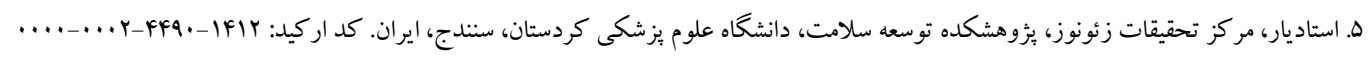

جكيuه

زمينه و هدف: فاسيوليازيس انسانى جزء بيمارىهاى انگلى منتقله از راه آب و غذا محسوب مىشود و در ايران، در مناطق

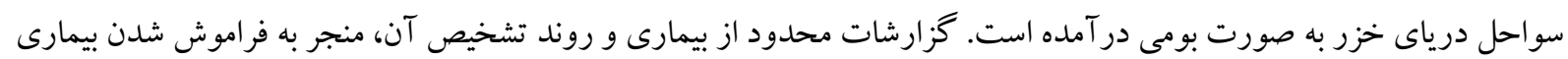

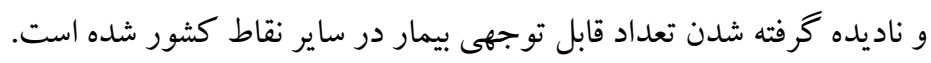

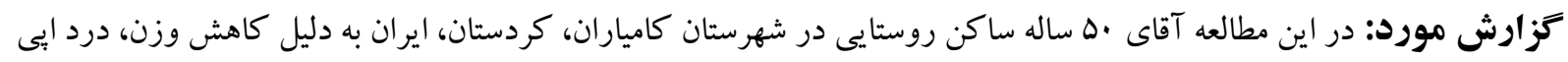

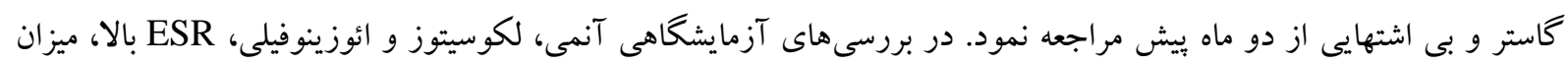

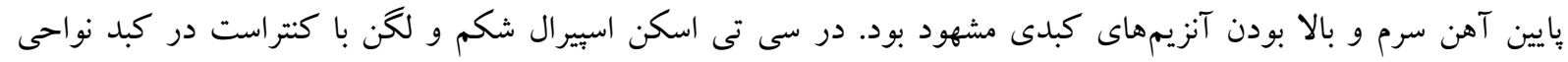

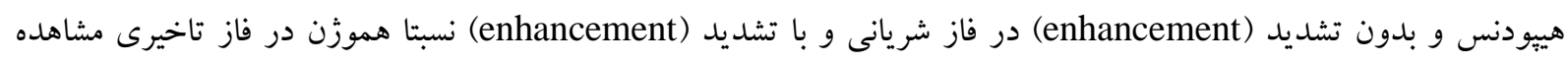

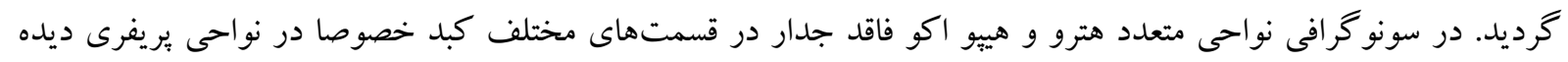

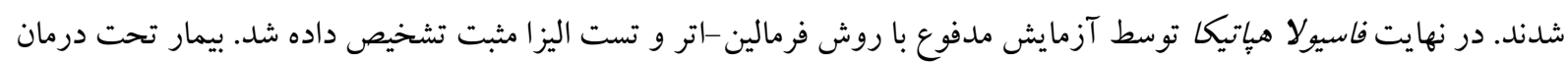

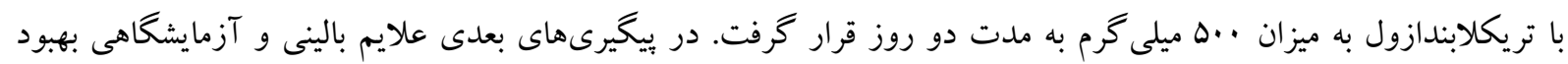

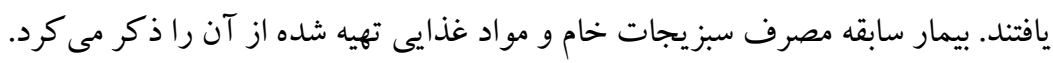

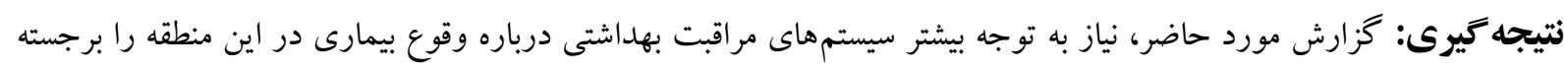
مى كند. وازههاى كليدى: فاسيوليازيس انسانى، فاسيولا هياتيكا، كردستان، ايران

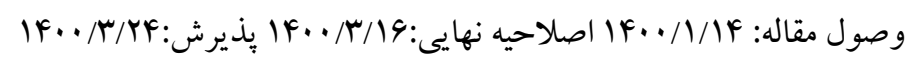


روش هاى سرولوزيكك و مولكولى در تشخيص فاسيوليازيس

$$
\text { توصيه مىشود (ه, \&). }
$$

در ايران، فاسيوليازيس انسانى در مناطق سواحل درياى خزر

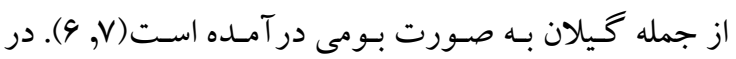

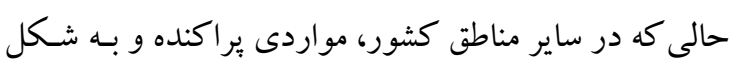

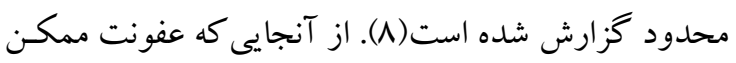

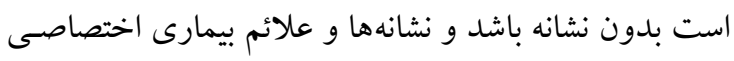

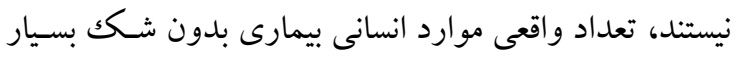
بيشتر از موارد گزارش شده مىباشد(Y). به نظر مىرسد علاوه بر دشوار بودن تشخيص دقيق بيمـارى،

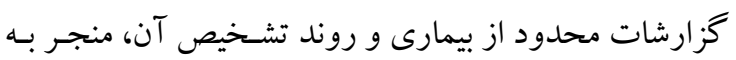
فرامـوش شـدن بيمـارى و ناديـده گرفتـهـ شــدن تعـداد قابـل توجهى بيمار در ساير نقـاط كشـور مسىشود. بنـابر اين ارائهـ

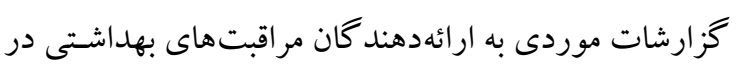

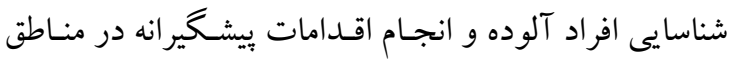
مختلف كمكك شايانى مى كند. در اين مطالعه مـا بـه معرفى

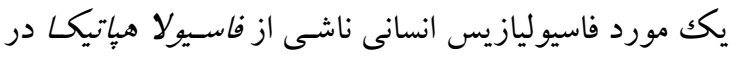
يكك بيمار •ه ساله ساكن روستايى در شهرستان كامياران كه

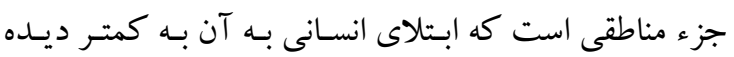
شده، مى يردازيم.

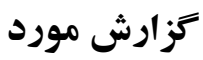

بيمار آقاى •ه ساله، سـاكن روستايى در اطراف شهرستان كامياران و كشاورز به دليل كاهش وزن (م كيلو در دو ماه)،

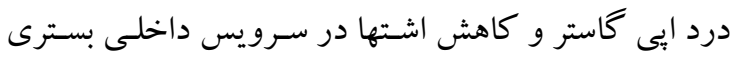

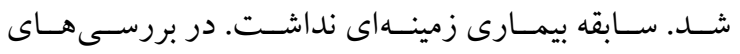
بيوشيميايى خون، همو كلوبين (Hb=1/\% g/dL)، شـمارش

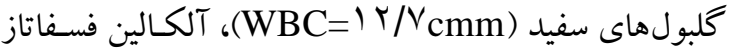
fr IU/L) ( ALP=rFv IU/L) 11 hr/mm) (AST=

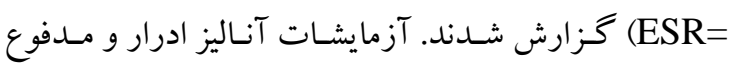

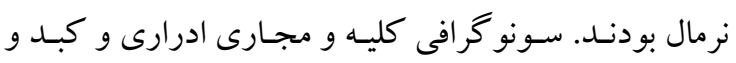

\section{مقدمه}

فاسيوليازيس انسانى جزء بيمارىهاى انگكلى زئونوز و منتقله از راه آب و غذا اسـت كه بـه دنبـال خـوردن متاسـر كرهاى عفونتزا (فرم آنكيسته ترماتود انگل فاسـيولا ) كـه غالبـا بـه

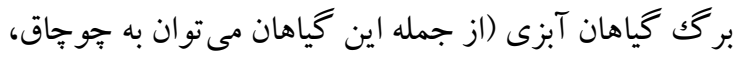

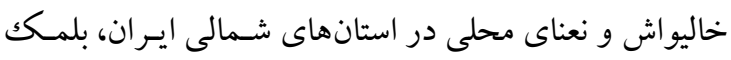

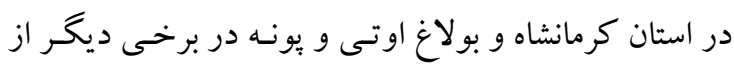
مناطق كشور اشاره كرد) جِبيده و يا بـه صسورت شـناور بـر آب وجود دارند، رخ مىدهد (1).

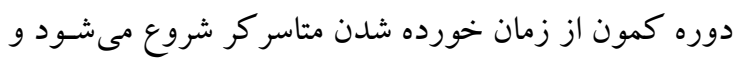
تا زمان ظهور اولين نشانه بيمارى را شامل مى شود و و به طـور

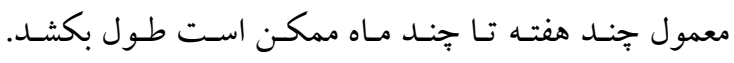

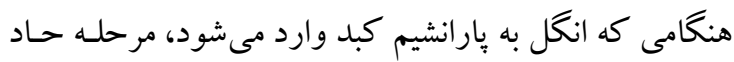

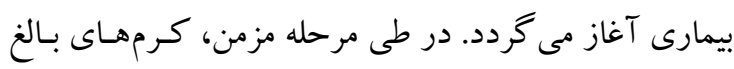
خود را به مجارى صفراوى متصل مى كنند و منجـر بـه ادامـه عفونـت بـه مــدت طـولانى مسى شـوند و در نهايست مرحلـه

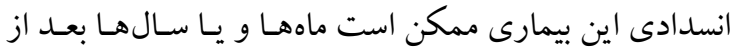

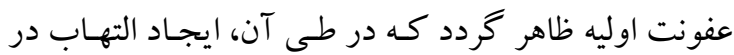

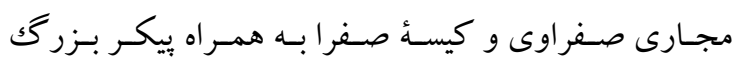

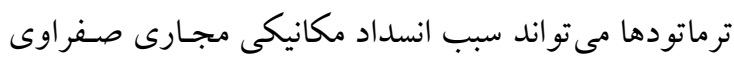
شوند(Y). فاسيوليازيس ممكن است بدون علامت باشد و يـا بهصورت علائم گوارشى، كوله سيستيت مزمن، كلانزيـت و

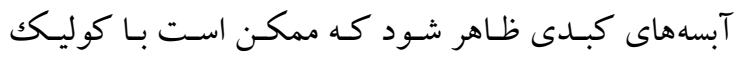

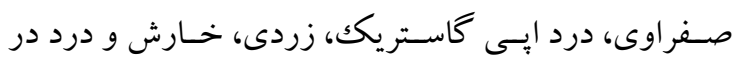
سمت راست ربع فوقانى شكم همراه باشد(r).

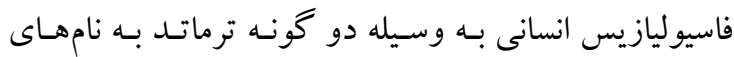

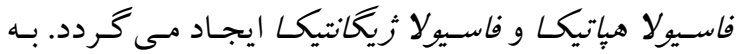

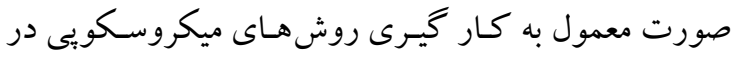
تشخيص و تفريق دقيـق ايـن دو گونه بـه دليل مشخصـات

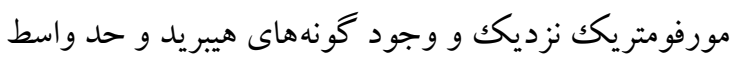
و همجنين وجود عفونت كاذب در نتيجه خوردن كبـد خـام يا نيم بز با مشكلاتى مواجه مىشود. از اين رو به كار گيـرى 
ضايعات جلدى، زردى، خارش يوست، آنمى، لكوسيتوز و ائوزينوفيلى با احتمال عفونت هاى انخلـى بـه سـرويس اوليـه عفونى ارجاع داده شد. در سونو گرافى كبد و كيسه صفرا، span كبد 190 ميلى متر

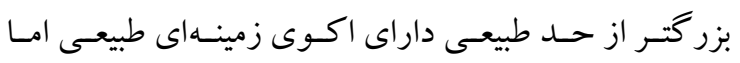
هتروزن بود. نواحى متعدد هترو و هييـو اكـو فاقـد جـدار در قسمت هاى مختلف كبد خصوصا در نسواحى يريفـرى ديـده

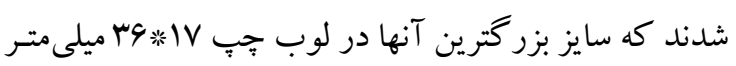

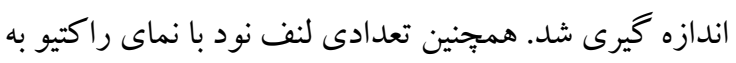

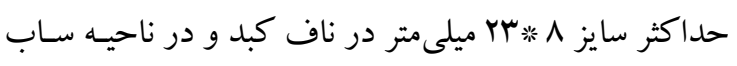
هياتيكك ديده شد. احتمال بروسه عفونى (فاز كبدى فاسـيولا هياتيكا ) در تشخيصهاى افتراقى مطرح كرديسد. دو كيست

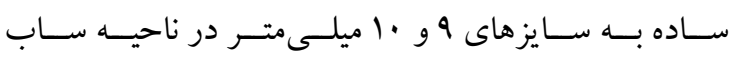
ديافر اگماتيكك لوب راست كبد ديده شدند. در نهايت نمونه مدفوع جهت تشخيص بيارازيتولوزى به آزمايشـاه دانشـاه علوم بزشكى ارسال و با روش فرمالين -اتر، تخمهاى بيضوى

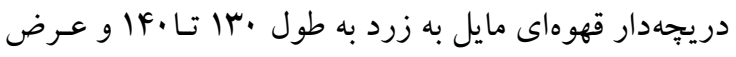

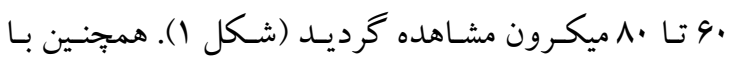
تست اليزا آنتى بادى IgG اختصاصى ضـد فاسـيولا هياتيكـا

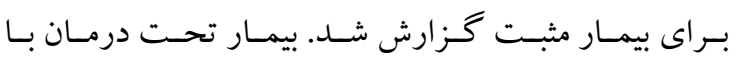
تريكلابندازول به ميزان .ه ميلى گرم به مدت دو روز قـرار كرفت(9). يكك هفته بعد از درمان علايم بالينى بهبود يافتند.

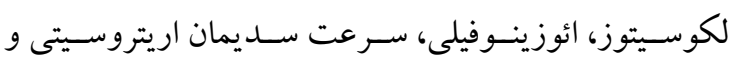
آنزيمهاى كبدى در ييخيرى يك ماه بعد به محدوده طبيعى رسيدند. لازم به ذكر است از بروز علايم تا تشخيص بيمارى

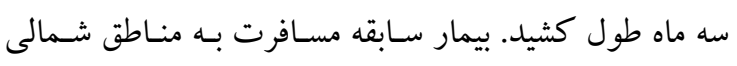

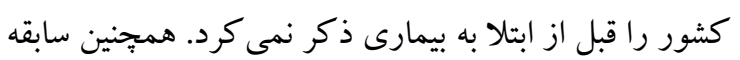

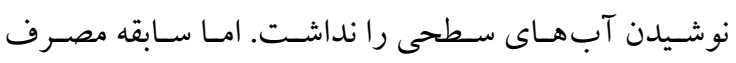

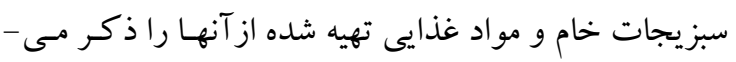
كرد.
كيسه صفرا نرمال بود و به دليل آنمى، اندوسكويى نيز انجام شد كه گزارش آن نرمال بود. يّ از انجام درمـان علامتى، بيمار از بيمارستان ترخيص شده بود. يكك ماه بعد به دليل تداوم درد شـكم و بـروز تـب و لـرز بـهـ كلينيكك بيمارى هـاى عفـونى مراجعـه نمـود. يافتـهــاى غيـر

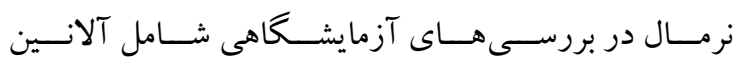
آمينوتر انسفراز (ALT=FA IU/L)

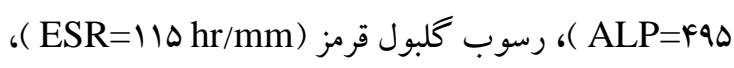

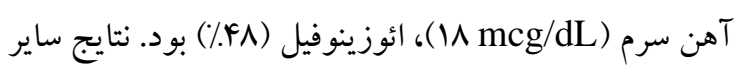
آزمايشـات شــامل ب-مر كايتواتــانول (Non-Reactive)، TSA (نرمال) و ميزان آنتى زن مخصوص بروستات TSH نرمال بـود. بـا توجـه بـه نتـايج آزمايشـات (آنمسى، سـديمان (ESR) كبدى) و وجـود علائسم يبوست (defecation disorder)، مشاوره گوارش براى بيمار درخواست گرديد. كولونسكويى انجام و نتايج آن نرمال بود. در سى تى اسـكن اسبيرال شكم و لكن با كنتراست در كبد نواحى هيبودنس و و بلدون تشديد (enhancement) در فاز شريانى و بـا تشـديد نسـبتا همـوزَن در فـاز تـاخيرى بـهـ نفـع (enhancement) همانزيوماتوز مشاهده كرديد. مجارى صـفراوى فاقـد اتسـاع اما در برخى نواحى هاييودانسيتى يرى داكتال و يرى يورتسال رويت شـد. كيسـه صـفرا حساوى دبـرى و فاقــ اتسـاع بـود.

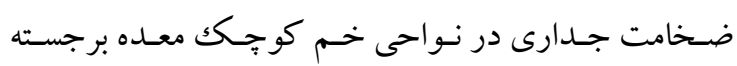
بود. تعدادى لنف نسود enhance شـونده در (prominent) نواحى برى سلياكك مشاهده گرديسـ. همجنـين مـايع آزاد در شكم و لكَن رويـت نشـد. بـا توجـه بـه علايسم بـالينى بيمـار

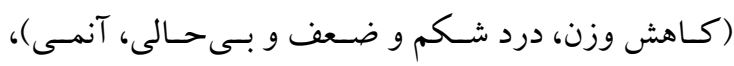

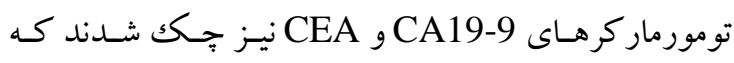

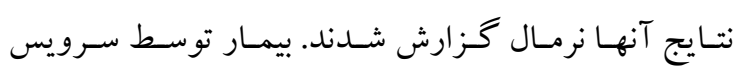

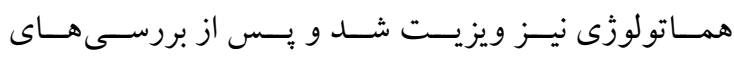

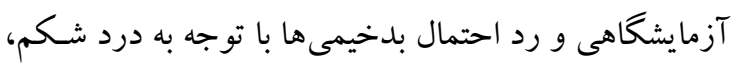




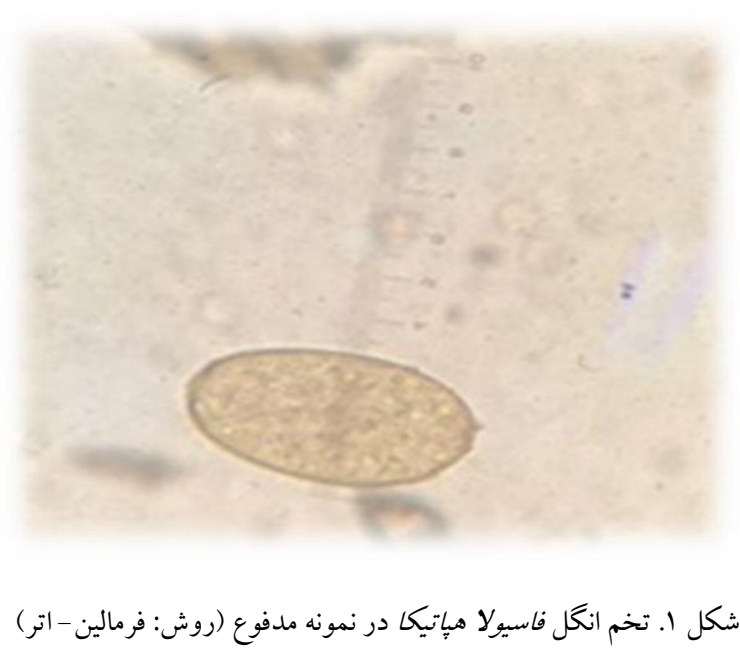

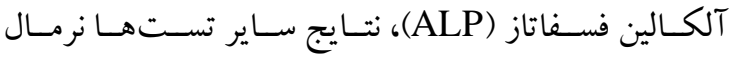

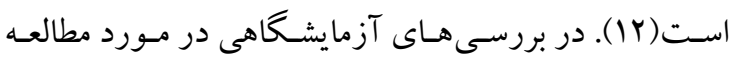
على رغم اينكه عفونت ناشى از انخـل فاسـيولا در انسـان بــ حاضر، از ابتداى بروز علايم بالينى در بيمار ميزان ALP و خوبى شناخته شده است اما به دليل بروز كم بيمارى ناشى از از

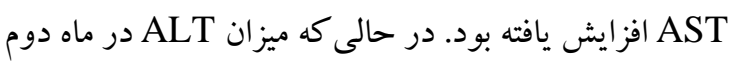
ارزيابى بيمار افزايش نشان داد.

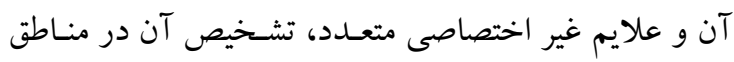
غير اندميك دشوار است.

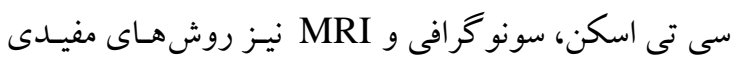

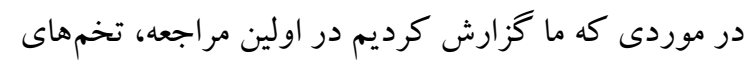

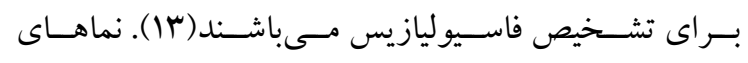
انكگل در آزمايش مدفوع رويـت نشـــ شـايد دليـل آن قـرار

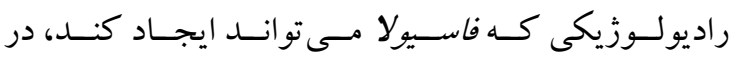
داشتن بيمار در مرحله حساد عفونـت باشـــ كـه در آن انشـل

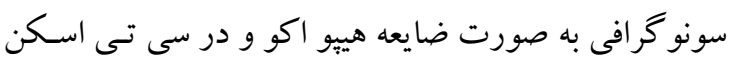

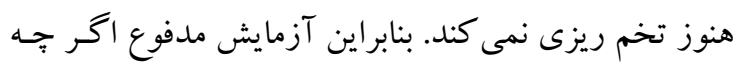

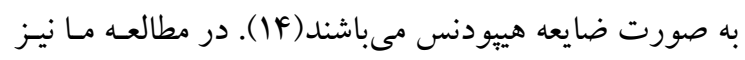

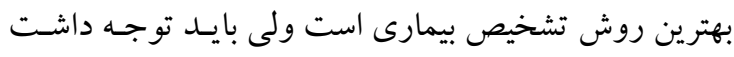

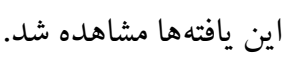

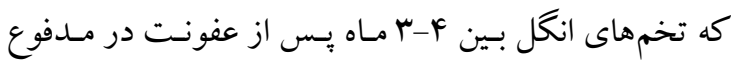

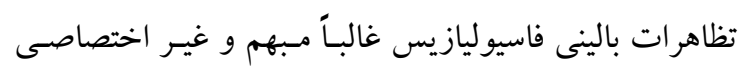

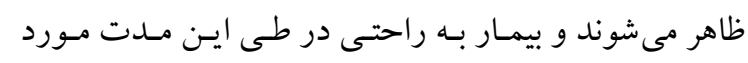
غفلت قرار مى گيرد (1).

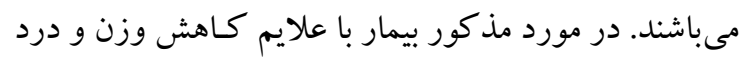

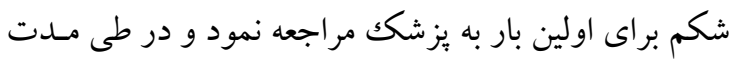

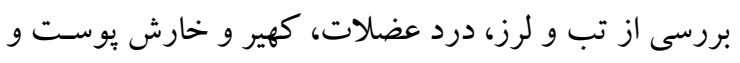

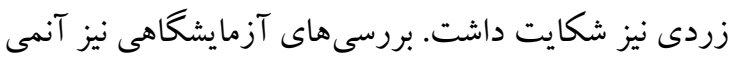

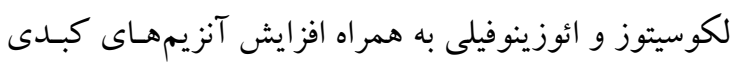

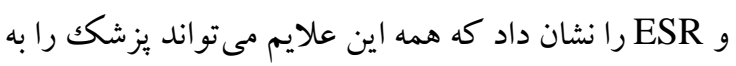

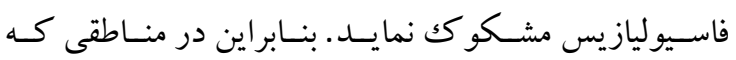

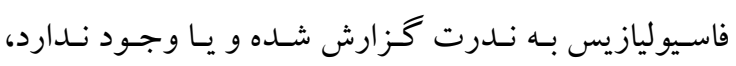
يز شكان بهتر است ايسن تشـخيص احتمـالى را مـد نظر قـرار

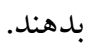

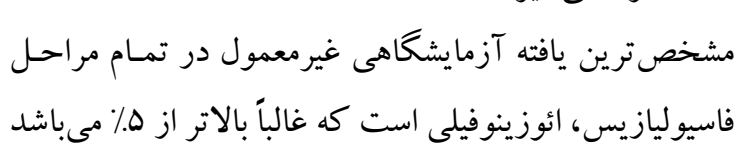

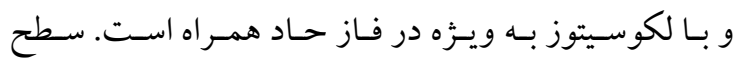

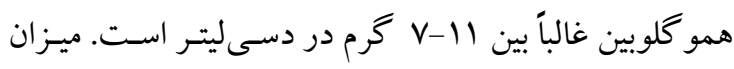
ESR متر در ساعت نيز برسد(11). تمام اين علايم در اين مورد نيز مشاهده گرديد. تست هاى غيرنرمال كبدى در هر دو مرحله حساد و انسـدادى كردي

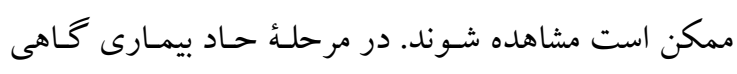

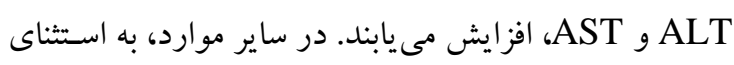




$$
\begin{aligned}
& \text { ممكن است طى ماههـايى از سـال در معـرض تمـاس بـا آب } \\
& \text { سابقه مسافرت بـه منـاطق شـمالى، سـابقه نوشـيدن آبهـاى }
\end{aligned}
$$

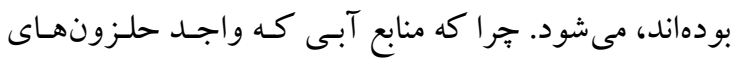

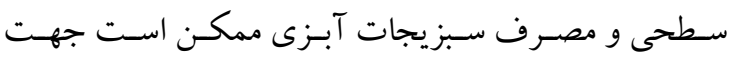

$$
\begin{aligned}
& \text { ناقل بوده و دامها به آن دسترسى داشته باشند، محيط بسيار } \\
& \text { تشخيص عفونت مفيد باشند. با اين وجود در مـورد گزارش }
\end{aligned}
$$

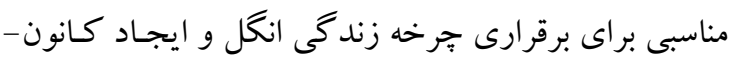

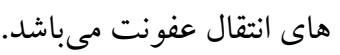

$$
\begin{aligned}
& \text { شده، بيمار فقط مصرف سبزيجات خام راذ كر نمود و به نظر }
\end{aligned}
$$

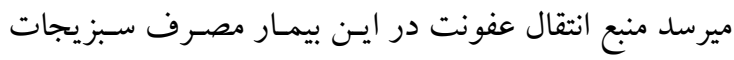

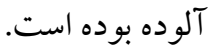

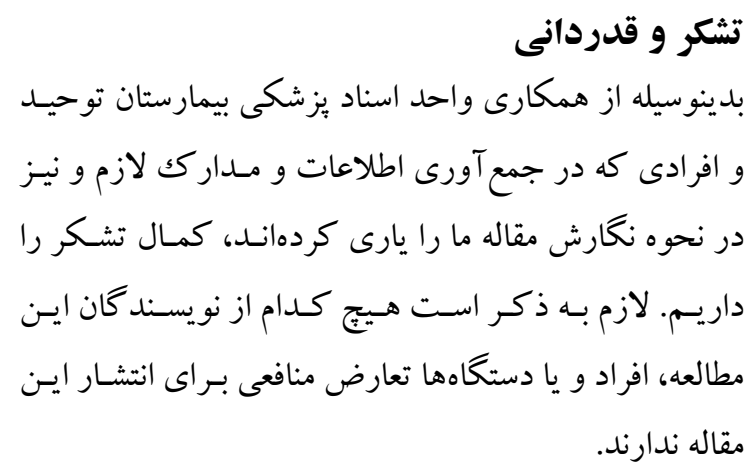

$$
\begin{aligned}
& \text { گزارش مورد حاضر، نياز به توجه بيشتر سيستمهاى مراقبـت }
\end{aligned}
$$

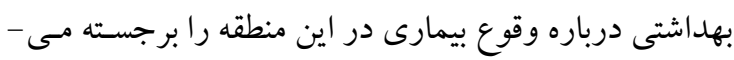

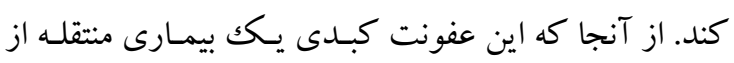

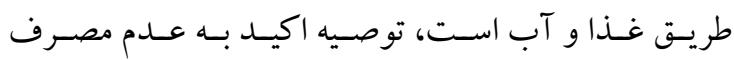

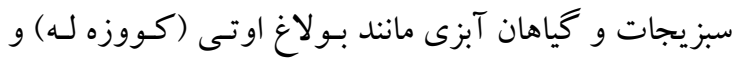

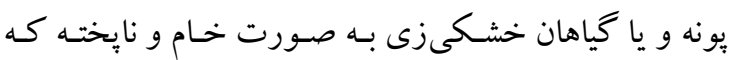

1.Ashrafi K, Bargues MD, O'Neill S, Mas-Coma S. Fascioliasis: a worldwide parasitic disease of importance in travel medicine. Travel Med Infect Dis. 2014;12(6):636-49.

2.Mas-Coma S. Parasitic diseases, global change and the developing world: the example of emerging fascioliasis. Sci Parasitol. 2007;1:10-21.

3.Piekarski G. Medical parasitology: Springer Science \& Business Media; 2012.

4.Ashrafi K, Valero M, Panova M, Periago M, Massoud J, Mas-Coma S. Phenotypic analysis of adults of Fasciola hepatica, Fasciola gigantica and intermediate forms from the endemic region of Gilan, Iran. Parasitol Int. 2006;55(4):249-60.

5.Itagaki T, Kikawa M, Sakaguchi K, Shimo J, Terasaki K, Shibahara T, et al. Genetic characterization of parthenogenic Fasciola sp. in Japan on the basis of the sequences of ribosomal and mitochondrial DNA. Parasitol. 2005;131(5):679.

6.Ashrafi K, Massoud J, Holakouei K, Mahmoodi M, Joafshani M, Valero M, et al. Evidence suggesting that Fasciola gigantica might be the most prevalent causal agent of fascioliasis in northern Iran. Iran J Public Health. 2004:31-7.

7.Ashrafi K. The status of human and animal fascioliasis in Iran: a narrative review article. Iran $\mathbf{J}$ Parasitol. 2015;10(3):306.

8.Heydarian P, Ashrafi K, Mohebali M, Kia EB, Aryaeipour M, Sharafi AC, et al. Seroprevalence of human fasciolosis in Lorestan Province, western Iran, in 2015-16. Iran J Parasitol. 2017;12(3):389.

9.Bennett JE, Dolin R, Blaser MJ. Mandell, douglas, and bennett's principles and practice of infectious diseases: 2-volume set: Elsevier Health Sciences; 2014.

10. Cox FE. History of human parasitology. Clin Microbiol Rev. 2002;15(4):595-612.

11.Webb CM, Cabada MM. Recent developments in the epidemiology, diagnosis, and treatment of Fasciola infection. Curr Opin Infect Dis. 2018;31(5):409-14.

12.Kaya M, Beştaş R, Çetin S. Clinical presentation and management of Fasciola hepatica infection: single-center experience. World J Gastroenterol. 2011;17(44):4899. 
13.Dusak A, Onur MR, Cicek M, Firat U, Ren T, Dogra VS. Radiological imaging features of Fasciola hepatica infection-a pictorial review. J Clin Imaging Sci. 2012;2.

14.Koç Z, Ulusan S, Tokmak N. Hepatobiliary fascioliasis: imaging characteristics with a new finding. Diagn Interv Radiol. 2009;15(4):247. 